\title{
SIMIOS, CIBORGUES Y REPTILES: \\ LA OVIPARIDAD EN OBRAS DE ESCRITORAS LATINOAMERICANAS DE CIENCIA FICCIÓN Y FANTASÍA
}

\author{
POR \\ M. Elizabeth Ginway \\ University of Florida
}

En los últimos años varios estudiosos han comentado sobre la presencia de un cyborg femenino latinoamericano, comparándolo con el modelo creado por Donna Haraway en "A Cyborg Manifesto", que aparece en su libro Simians, Cyborgs and Women: The Reinvention of Nature (1991). Los seres femeninos poshumanos que figuran en obras de escritoras como Alicia Borinsky, Eugenia Prado y Carmen Boullosa se han citado como representativos del papel de la mujer en sociedades posdictatoriales o distópicas latinoamericanas como las que han estudiado Jerry Hoeg, Andrew Brown, Diana Niebylski y Claire Taylor. Sin embargo, el modelo de Haraway no trata la cuestión de la reproducción porque la figura del cyborg femenino existe fuera de los patrones de reproducción y domesticidad impuestos por la sociedad capitalista patriarcal.

Mientras que Ginway ha comentado la reproducción sexual de los cyborgs en textos brasileños ("Do implantado" 792-794) y Jerry Hoeg ha desarrollado la idea de "cibormestiza" (99), hay varios textos latinoamericanos que contemplan la reproducción fuera del cuerpo femenino, a través de un proceso paralelo a la oviparidad reptil. ${ }^{1}$ Este proceso conserva la marca de la maternidad, pero la sitúa fuera del cuerpo y la reproducción convencionales. Así, la maternidad se convierte en una especie de espacio creativo e híbrido, que concibe la experiencia del cuerpo femenino de forma distinta, reconfigurando las relaciones entre los sexos y entre la mujer y su cuerpo. Esta forma de reproducción permite a la mujer una experiencia intermedia entre la independencia absoluta del cyborg y la dependencia de la maternidad convencional.

En este artículo, analizo cuatro narrativas principales escritas por autoras latinoamericanas en las que figura la oviparidad: dos cuentos, "O ovo do tempo" (1994)

\footnotetext{
En la ciencia ficción existe una tradición de la monstruosidad de seres alienígenas que reproducen por oviparidad, como en A Princess of Mars (1917) de Edgar Rice Burroughs con su sensual princesa, Dejah Thoris, y en The Lovers (1952) de José Philip Farmer. En estas obras la idea de reproducción ovípara va más para resaltar la diferencia entre extraterrestres y seres humanos que comentar la cuestión de reproducción y papeles de género.
} 
de Finisia Fideli (Brasil), e "Intermedio del hombre verde (20--)" (1999) de Marta Aponte Alsina (Puerto Rico) y dos novelas, Lóbulo (1998) de Eugenia Prado (Chile), y Animal sobre la piedra (2008) de Daniela Tarazona (México). En estos textos se describen experiencias que combinan lo cyborg y lo humano, lo masculino y lo femenino y lo mamífero y lo reptil, rompiendo así las jerarquías establecidas y las clasificaciones convencionales. De la presencia del huevo o "óvulo" en estos textos femeninos surgen cuestiones relativas al proceso reproductivo que exploran la identidad sexual y la realidad social, sobre todo con respecto a la idea de la maternidad.

Como veremos, los marcos teóricos de Haraway, Hayles y Butler ofrecen maneras de re-pensar el cuerpo poshumano o posgénero, pero no son del todo adecuados para los textos "ovíparos". Por eso, conviene aprovechar el pensamiento de feministas francesas como Hélène Cixous, Luce Irigaray y Julia Kristeva para profundizar en las ideas de la corporalidad y el cuerpo reproductivo. Estas autoras "escriben el cuerpo" para subvertir el discurso masculino, evocando la sensualidad o "jouissance" de la experiencia del cuerpo feminino en toda su fisicalidad (Ives 49-52). La maternidad es, sin duda, un área controvertida dentro del feminismo, y es Kristeva quien retrata en detalle la ambivalencia del cuerpo materno y el sentido de poder del cuerpo femenino en su función reproductiva.

Kristeva distingue entre el poder materno asociado con el cuerpo, y el paterno, asociado con el lenguaje y el orden simbólico (Kristeva, "Maternity" 180), y descubre la tensión entre estas dos áreas de autoridad en las representaciones de la Virgen María en obras renacentistas (Ives 119-122), imágenes que nos remiten a la centralidad de la iconografía de la Virgen en América Latina. Según Emily Hind, aunque sí es permisible parodiar a Sor Juana en México, la Virgen María sigue siendo una figura tabú en las obras de escritoras mexicanas (39) y en América Latina en general. Además, Hind afirma que el grado de ambición literaria de escritoras contemporáneas como Boullosa está en relación inversa con la femeninidad/maternidad con que se presentan públicamente (50).

Las obras de ciencia ficción y fantasía de este estudio convierten la reproducción humana en ovípara, exponiendo la reproducción a la luz del día, en un espacio neutro, fuera del cuerpo de la mujer. Como la maternidad exige un gran sacrificio físico y mental a la mujer, al transformarla en algo más abstracto y extraño, se redefine el lugar de la maternidad en la sociedad, haciéndola más intelectual y menos sentimental y "femenina". Al representar el embarazo en forma de huevo, se desloca y parodia el lenguaje de la naturalidad o sacralidad de la reproducción y la maternidad. ${ }^{2} \mathrm{Al}$ trocar el cuerpo femenino por un cuerpo réptil y mutable, los textos ovíparos recuerdan la risa

\footnotetext{
Quizá el primer cuento latinoamericano escrito por una mujer con una imagen de oviparidad sea "Los embriones del violeta" (1973) de Angélica Gorodischer. El ser alienígena de este planeta ofrece a los náufragos humanos la satisfacción de sus más profundas necesidades psíquicas. Entonces, cuando uno de los tripulantes se convierte en un hombre-feto, pasa a vivir en un tipo de huevo-útero.
} 
desafiadora de la Medusa de Hélène Cixous (257) en sus parodias de obras "maestras" o "másculas". Al mismo tiempo, cuando transfieren la oviparidad al macho, dándole síntomas de mareo y otros males del embarazo, los textos alternan entre la risa paródica y un anhelo transformativo. Como textos de ciencia ficción y fantasía, retratan la maternidad convencional como una experiencia peculiar y perturbante, con el cuerpo reproductivo en el centro del texto, llamando la atención sobre la ausencia de la maternidad en las letras latinoamericanas.

\section{Maternidad, oviparidad y parodia en Finisia Fideli y Marta Aponte Alsina}

El primer texto del conjunto contemporáneo en que figura la oviparidad fue escrito por la brasileña Finisia Fideli. Este cuento, "O ovo do tempo" [El huevo del tiempo] (1994), puede ubicarse dentro de la ciencia ficción por su uso de motivos conocidos del género como el viaje en el tiempo, clonaje de dinosaurios, y un impulso utópico. Es la única narrativa escrita por una mujer en una antología temática sobre dinosaurios Dinossauria Tropicalia (1994), publicada en Brasil durante la época del estreno de la película Jurassic Park (1993). Los cuentos de Fideli ofrecen un ejemplo de la escasa ciencia ficción escrita por mujeres durante los ochentas y noventas, y su feminismo se muestra en su uso de una voz masculina y la colocación de mujeres en profesiones tradicionalmente consideradas masculinas. ${ }^{3}$ La cuestión feminista es siempre parte de la temática de sus cuentos, ${ }^{4}$ y "O ovo do tempo" no es una excepción a esta regla.

A pesar de ser el más convencional de los cuatro textos, tanto en su forma como en su mensaje, intenta reconciliar la reproducción y la carrera profesional a través de la imagen de los dinosaurios, una especie ovípara. Fideli relata la historia de Mariana, una científica especializada en la conservación de recursos naturales, quien, al comprar un geodo en forma de huevo por instigación de una amiga, forja a través de él conexiones con distintos reinos filogénicos y épocas temporales. El geodo es un vínculo con el pasado - contiene el ADN de una raza extinta de dinosaurios- y con el futuro - a través de un grupo de científicos futuros que un día resuscitarán los reptiles extintos activando su código genético-. Cuando Mariana descubre que el geodo tiene extraños poderes, se dirige al sur del país para devolverlo a su lugar de origen, un depósito de otros huevos/ geodos dentro de una mina activa. En la caverna, ve a un extraño ser que parece ser un astronauta o cyborg de sexo indeterminado que pretende ser cuidador de los huevos/ geodos. Finalmente Mariana se da cuenta de que se trata de una mujer, desciendiente suya y científica, que ha viajado en el tiempo para proteger el depósito.

3 Sobre autoras de ciencia ficción brasileña, se puede consultar a Ginway, "Recent Brazilian Science Fiction and Fantasy Written by Women."

4 Consulte a Ginway, "Finisia Fideli: Finding the Female Voice in Brazilian Science Fiction" para comprender el contexto de Fideli. 
A partir de este momento, Mariana tiene una visión de una sociedad altamente científica e igualitaria que contrasta con la sociedad corrupta e injusta brasileña. Por ejemplo, al acercarse a la mina, es testigo de las operaciones de un grupo de contrabandistas. Sabe que si la descubren, será "eliminada" por los criminales, delito inconsecuente para ellos y para las autoridades. A pesar de este peligro, Mariana empieza a tener inesperados sentimientos maternos hacia el geodo que parece comunicarse con ella por inexplicables movimientos y señales. Pero en vez de maravillarse de estos sucesos -reacción típica de los protagonistas de ciencia ficción-Mariana simplemente se siente mareada, síntoma típico del embarazo. Al final del cuento, Mariana siente un impulso irrestible de regresar a casa y establecer una vida doméstica con hijos. De esta manera, el cuento re-escribe Jurassic Park desde un punto de vista femenino, sustituyendo a los palentólogos aventureros por una mujer que no desea luchar contra dinosaurios sino entregarse al embarazo. Siguiendo este pensamiento, nos damos cuenta de que el episodio del geodo es una especie de "anunciación" de su embarazo. El hecho de que la protagonista se llame Mariana - una referencia al marianismo- parece reforzar esta interpretación esencialmente paródica de la obra.

La visión utópica que figura en el cuento de Fideli demuestra un espíritu de optimismo brasileño y sus logros en cuestiones de tecnología y ciencia, dignos de un país grande. La escritora puertorriqueña Marta Aponte Alsina proporciona una visión más reservada y crítica del futuro en su cuento "Intermedio del hombre verde (20--)" (1999), reflejando quizá la actitud de los habitantes de una isla pequeña. La trama de este cuento es, en parte, una parodia de Frankenstein (1818) de Mary Shelley. En el escenario principal de "Intermedio", encontramos al protagonista Jack Wald, autor machote de comics, contando a unos amigos la historia de un monstruo, paralela a la retratada por Mary Shelley en la introducción que añadió en 1831 a su famosa novela, donde revela cómo tuvo la idea para su criatura (22). Jack ha recibido un correo electrónico de una entidad llamada Naxos (¿anagrama de "saxon" anglosajón?) con un adjunto lleno de imágenes de monstruos de varios tipos. Sigue el tema de roles de género cuando Jack se refiere a su propio proceso creativo en términos femeninos. Inspirado por sus aficionados, concibe a su cerebro como de un tipo de horno capaz de crear monstruos: "Cociné aquellas ideas en hornilla trasera donde hervía y deshuesaba ideas" (128). Incluso llega a sufrir jaquecas parecidas a "dolores de parto" (128-129). Decide elaborar uno de los monstruos, un reptil aterrador, pero igual que en la obra de Shelley, el creador le niega una pareja hembra. Jack opta, por el contrario, por un reptil de sexualidad ambigua o más bien hermafrodita, pues decide hacerle ovíparo:

El tamaño de aquel bicho compensaba pequeñeces. Pero de qué servirá semejante palo, la grandeza de una polla, un gallo tan púrpura, una pinga reluciente, si el diablo que lo lucía era el único en su especie. O le devolvía a su hembra adoradora, o le permitía 
preñarse a si mismo. Hice lo más digno. Mi criatura pariría sin joder a una pareja, mi macho pondría huevos. (130)

Más tarde, Jack, que parece estar alucinado, cuenta que el monstruo se ha asomado a la puerta, pidiéndole misericordia, contándole su sufrimiento y aislamiento afectivo, igual que las quejas del monstruo de Frankenstein para con su creador. Pero en este momento, Jack se convierte en su propia creación, con escamas y un pene enorme, devorando a todos los que escuchaban su relato. La única sobreviviente es Marcela, y cuando el monstruo Jack le pide una noche de amor, se despierta de un sueño y, en un momento metaficcional, se da cuenta de que todo ha sido inspirado por la imagen de un monstruo en la portada de un comic que leía en la playa antes de dormirse mientras su marido e hijo se bañaban en el mar. En este momento, descubre un huevo inexplicablemente semi-enterrado en la arena.

Si pensamos en la cuestión de la oviparidad y la creación, vemos que el huevo es la conexión entre las dos partes del cuento, el monstruo ovíparo en la primera parte y el huevo en la segunda. Primero Marcela piensa cocinar el huevo en una tortilla, o dárselo a las hormigas [otra raza ovípara], pero finalmente decide enterrarlo de nuevo. Como está en la playa con su familia, opta por lo último, una solución parcial, un "intermedio" que evita conflictos entre su papel de madre y el significado trascendental del huevo.

El título del cuento, "Intermedio del hombre verde (20-)..." puede aludir a este espacio ambiguo también, y al punto intermedio entre sexo masculino y femenino, monstruo y humano, pesadilla y sueño despierto. Curiosamente, no hay ningún hombre verde en el cuento; quizá sea una referencia al típico tripulante de platillo volador de los comics y películas de los cincuenta. A través de la referencia al huevo, Aponte alude a la reproducción de los monstruos femeninos de películas norteamericanas, empezando con la reina de las hormigas radioactivas de Them! (1954) de Gordon Douglas, a los capullos ovíparos de Invasion of the Body Snatchers (1956) de Don Siegel, y a la mujer gigantesca y destructiva de The Attack of the Fifty-Foot Woman (1958) de Nathan H. Juran. El colmo de la hembra alienígena es el monstruo de la película Alien (1979), de Ridley Scott, en que la reproducción ovípara combinada con la imagen devoradora de la boca del monstruo recuerda a la vagina dentada (Bell-Metereau 14), y el miedo al carácter sumamente biológico del cuerpo femenino y el proceso de reproducción. ${ }^{5}$ El huevo, que tiene un cascarón duro por fuera, pero por dentro está lleno de líquidos abyectos asociados con el cuerpo femenino, recuerda el sentido kristeviano del horror. Al utilizar la imagen del huevo y la oviparidad, Aponte evoca lo abyecto y la ruptura

\footnotetext{
Se puede notar esta ansiedad reproductiva/creativa en Frankenstein, y sus orígenes góticos que tienen conexión fuerte con la maternidad, ideas desarrolladas por feministas de los setentas como Ellen Moers, quien explora la pérdida y el sentido de culpa de Mary Shelley por la muerte de su hijo ilegítimo de tres meses (91-99).
} 
de fronteras del orden simbólico, de forma subversiva (Kristeva, "Powers" 232). Así, se plantea otro modelo de creatividad literaria lista para quebrar el huevo, capaz de "romper" tabúes de géneros literarios y sexuales. ${ }^{6}$

El RePtil, ReProducción ovípara y trauma en Eugenia Prado y Diana Tarazona

En Lóbulo (1998), de la autora chilena Eugenia Prado, la protagonista vive en una casa en Santiago con su madre, con quien pelea constantemente porque la madre se rehusa darle informaciones sobre su padre, de quien Sofía guarda sólo una foto. Quizá por eso se encuentra deprimida, inmóvil y apática menos cuando habla por teléfono con un hombre misterioso, cuya voz la activa prácticamente como un organismo cibernético (Brown 62). Esta interpretación se refuerza por el hecho de que, cuando muere Sofía al final de la historia, se le sale por la boca un texto como si hubiera sido un tipo de impresora, en un tipo de experimento fracasado de hibridez cibernética (Brown 7374). Otra interpretación posible se basa en la experiencia de Prado con la dictadura de Pinochet. En una entrevista con Kryzystof Kulawik publicada en 2012, Prado revela que llevó casi diez años elaborando Lóbulo (233), a partir de 1988, fecha del plebiscito contra Pinochet, y admite, "Viví y me desarrollé durante la dictadura y tenía una deuda con eso" (239). Por un lado, parece que la muerte de Sofía puede interpretarse como sacrificio para llamar la atención a lo irrepresentable de las atrocidades de esa época; y por otro, simboliza la incapacidad de una mujer para adaptarse a la realidad contemporánea tecnológica. Los temas de traición, rivalidad y tragedia parecen permear la narrativa, y la rebeldía de Sofía se parece a la de Electra, figura mitológica quien se venga de su madre por su adulterio y el asesinato de su padre. ${ }^{7}$

Sin embargo, cuando Sofía da a luz a un texto en forma de un "hueco/huevo/ló(v) ulo" (210), surge el tema de la oviparidad, resultado de un extraño embarazo. Sofía dice tener la sensación de una serpiente que la muerde por dentro. En mi interpretación, esta serpiente es la voz masculina que, desde el teléfono, la penetra o entra por el lóbulo (de la oreja), para pasar al "lóbulo" del cerebro. Una vez fertilizado, el óvulo crece en el cerebro en vez del útero, lo cual explica por qué a Sofía se le sale un texto de la boca en vez de un bebé del útero.

Por un lado, la serpiente es un símbolo fálico que penetra a Sofía misteriosamente como representación de la inescapabilidad del discurso patriarcal y el simbolismo del pecado que le impone el catolicismo. Por otro, la serpiente también puede ser un

6 Como ha señalado Verónica Dávila, el cuento es, en parte, una alegoría de la falta de inclusión de escritoras en el canon puertorriqueño (16), y su uso de ciencia ficción subvierte la autoridad masculina al apropiarla y parodiarla.

7 En la trilogía de la Orestídia, Electra y Orestes conspiran vengarse de su madre por asesinar a su padre, Agammenón, después de su llegada de la guerra de Troya. 
símbolo de la regeneración del oroboro, la culebra que se muerde la cola, símbolo de la auto-fecundación o transformación (Cirlot 246-247). El nombre Sofía -del griego sophos "sabio" - igual que la serpiente, símbolo de la sabiduría prohibida o tabú.

Si la oviparidad en esta obra indica un proceso circular y fracasado del texto/óvulo -como sugiere Brown- puede ser una representación de un proceso inacabado, quizá de luto por el tiempo de la dictadura.

Así, la oviparidad de Sofía es creativa y destructiva a la vez: el huevo/texto que produce por la boca origina en un lóbulo de su cerebro, y la combinación de libro/+óvulo, resulta en el "lóbulo" misterioso, un huevo de serpiente que retrata la dificultad de reconciliación, un "óvulo" que es el texto, imperfecto e ilegible, que, al fracasar en su propia enunciación, significa un acto de sacrificio y creatividad, insertando el cuerpo de la mujer en el centro del drama colectivo y personal.

En la entrevista con Kulawik, Prado enuncia su propia interpretación de la historia de Lóbulo, basada aparentemente no tanto en el texto sino en sus propios pensamientos ulteriores. Dice, "Mi personaje se transforma en serpiente, eliminando la piel que la cubre, luego sus órganos se comprimen y la morfología se re-organiza para adoptar un cuerpo 'otro' de reptil" (Kulawik 236). Según esta lectura, la protagonista de Lóbulo no sería del todo víctima, sino que pasaría por una metamorfosis con la cual el texto se aproxima más a un texto fantástico en que coexistirían lecturas de hibridez cibernética e hibridez reptil.

El tema del cuerpo reptil está aun más aparente en la obra de Diana Tarazona. Señalada entre las mejores novelas del 2008 (González 2), El animal sobre la piedra (2008) pertenece al género fantástico más bien que a la ciencia ficción, y ha sido comparada a La metamorfosis (1915) de Franz Kafka por la transformación corporal de su protagonista. Sin embargo, Tarazona dice que su obra es distinta de la de Kafka por las dudas que deja sobre la transformación de la protagonista Irma (Gutiérrez 7), rasgo que nos recuerda la "vacilación" formulada por Todorov entre lo natural y lo sobrenatural en los textos fantásticos. Al leer la novela, vacilamos entre una interpretación natural y científica de los eventos narrados y otra sobrenatural o fantástica. Fuente de nuestras dudas es la aparente naturalidad con que Irma cuenta los eventos fantásticos en una voz narrativa casi monótona.

Como en muchos textos fantásticos, la narradora no es completamente confiable. Después de la muerte de su madre, Irma decide ir a una ciudad balnearia, donde el calor parece afectar su cuerpo de tal forma que, poco a poco, su piel se transforma en escamas, y sus brazos y piernas en patas de cuadrúpedo. En un tono neutro, comenta que ha empezado a escupir veneno y que ha logrado inseminarse como una rana. Cuando se prepara a "desovar" cerca de un arroyo, su metamorfosis comienza a mezclarse con detalles una internación hospitalar.

A estas alturas, el hecho de que Irma haya mencionado al comienzo del relato la marca de suero en su muñeca empieza a cobrar sentido, ofreciendo otra interpretación de 
los sucesos. Por ejemplo, cuando una enfermera comenta que Irma había sido encontrada desnuda andando por la ciudad, Irma ni confirma ni desmiente esto. Al conversar normalmente con la enfermera y el médico sobre su condición física, súbitamente menciona que el huevo del que va a nacer su hija está en la silla del cuarto, y les pide que lo pongan al sol para calentarlo. Al final de la novela, Irma baja de la cama y parece encogerse y convertirse en cuadrúpedo de nuevo. Una vez en el suelo, encuentra el huevo, pero cuando lo toca descubre que está vacío.

Aunque no sabemos exactamente a qué se refiere el huevo "vacío" de Irma, se presentan varias posibilidades: puede representar una depresión provocada por la muerte de su madre, un sentido de culpa, o un hueco psicológico que no logra llenar. En cierto momento, Irma se refiere a la naturaleza ovípara de las ranas, pensando en cómo, de niña, cazaba renacuajos con una amiga. Comenta: "Estábamos seguras, sin que supiéramos por qué, de que esos renacuajos vivían solos, nunca pensamos en sus madres. Pero las ranas no regresan a ver a sus hijos: teníamos razón" (152). Esta independencia psicológica es lo que Irma no logra realizar por completo, porque todavía intenta escaparse de la culpa provocada por la muerte de su madre, o, posiblemente, de su hija. Lo que desea Irma es no sentir ni la culpa ni el dolor de la pérdida, y la sangre fría del reptil parece apta para experimentar dolor sin perder el control emocional y físico. En cierto momento Irma se pregunta, "Si estoy transformándome en un reptil, ¿mi descendencia será ovípara?" (80), como si quisiera esto para su hija, otro modo de ser o entender el cuerpo reproductivo o creativo. Cuando la enfermera se refiere a la "placenta real" (168) de Irma, quizá como señal de un mortinato, parece que toda su experiencia ha sido imaginada, un relato fantástico de metamorfosis y de pérdidas reales e imaginadas.

Así, se ve que una hembra reptil ovípara puede referirse tanto a un ser físico como a una experiencia emocional o intelectual. El deseo de participar y redefinirse después de un trauma y lograr expresarse por la combinación de un reptil grotesco y un huevo puro, les ofrece a estas escritoras maneras alternativas de imaginar el cuerpo físico y la reproducción en sus propios términos, sin sentimentalismo melodramático, pero con poder físico y creativo.

PARA RE-PENSAR EL CUERPO OVÍPARO Y LA ESCRITURA

La reproducción ovípara llama la atención a la maternidad sin el marco convencional del cuerpo materno. Al ofrecerle a la mujer una alternativa para su reproducción, aunque sea parcial o ficticia, sugiere otras maneras de examinar las relaciones madre/hija, mujer/ hombre y mujer/texto. Se trata además de textos fantásticos más bien de pura ciencia ficción, lo que también nos hace cuestionar los límites entre la clasificación de géneros literarios. En su ensayo "The Law of Genre" [La ley del género] (1980) sobre un texto 
de Bataille, Derrida insiste en que no se debe mezclar géneros, ni reinos filogénicos, ni sexos. Claro que lo dice de forma irónica, porque es imposible aislar términos en paradigmas o taxonomías de géneros, porque las categorías no son nunca absolutas. Por un lado, los géneros sexuales que parecen fijos y naturales esconden la necesidad/la violencia de la represión, representada por la autoridad, la lógica y el orden que permiten que la sociedad funcione. Por otro lado, la ambigüedad del ensayo de Derrida sugiere el poder trangresivo de la alteridad o feminización, un concepto aun más claramente visible en la reproducción ovípara que tiene lugar dentro y fuera del cuerpo femenino. Esta alteridad abre un espacio para emociones polivalentes hacia el poder del cuerpo femenino, que también cuestiona divisiones de género sexual y género literario.

Al examinar cuatro textos "ovíparos" de escritoras latinoamericanas, hemos visto conflictos entre las expectativas convencionales de la familia y el rol materno en sociedades tradicionales por una parte, y por otra, las ambiciones de mujeres que quieren contribuir y renovar el cuerpo político y social a través de su literatura. Esto sugiere que un cuerpo reproductivo fuera de las normas convencionales es una manera de captar el espíritu de parodia o subversión de la reproducción tradicional y del cuerpo femenino, en contraste con los modelos de cyborgs y poshumanos de Haraway y Hayles, o de los modelos feministas performativos de Judith Butler, modelos que han sido aplicados a varios textos de escritoras contemporáneas. ${ }^{8}$

\section{CONCLUSIÓN}

La oviparidad intenta incorporar la reproducción sin el escencialismo de la maternidad convencional. Representa un tercer camino: ni completamente humano, ni animal, ni reptil. Tampoco participa en experimentos de clonaje, ni de cibernética. La oviparidad en mujeres evoca la idea de monstruosidad, pero en el sentido de que el monstruo rompe las fronteras normales o naturalizadas de las leyes impuestas por la sociedad (Cohen 6) y, en este caso, las que regulan la reproducción de la sociedad patriarcal. El cuento de Fideli sugiere otras maneras de valorar la reproducción y ampliar la participación femenina en la sociedad, sin reducir la mujer a su función reproductiva, dado que los dinosaurios y su oviparidad le ofrecen a la protagonista una conexión científica profunda al pasado y al futuro. En el caso del texto de Aponte Alsina, evoca con el huevo asociaciones paródicas con el género de ciencia ficción a través de las alusiones al texto matriz de Mary Shelley para comentar y articular el dilema de crear una ciencia ficción femenina. La oviparidad en el texto de Prado le ofrece maneras de representar una creatividad pasiva y activa, jugando con significados de lóbulo y óvulo,

\footnotetext{
Además de los estudios de Niebylski y Taylor, hay también los de Kuhnheim y Gundermann, que usan el marco feminista para estudiar las obras de Boullosa.
} 
cuestionando la posibilidad de crear y destruir en un momento de trauma personal o coletivo. La metamorfosis experimentada por la protagonista de Tarazona deriva del deseo de protegerse y expresar dolor físico y emocional, de "sangre fría". Los textos no evitan la sexualidad ni la fisicalidad de la mujer, sino intentan reinventar maneras de imaginar el cuerpo y roles sociales femeninos. Sin negar la reproducción física, social y artística, tratan de redefinir su corporalidad cuestionando lo que significa ser "productivo" en la sociedad. El hecho de que la oviparidad figure de forma independiente y diferenciada en cuatro historias de los últimos veinte años indica que se trata de un concepto original dentro del feminismo latinoamericano.

\section{BiBLIOGRAFÍA}

Aponte Alsina, Marta. "Intermedio del hombre verde (20--)". La casa de loca. Cayey: Sopa de Letras, 1999. 123-133.

Bell-Metereau, Rebecca. "Woman: The Other Alien in Alien." Woman World Walkers: New Dimensions of Science Fiction and Fantasy. Jane B. Weedman, ed. Lubbock: Texas Tech P, 1985. 9-24.

Borinsky, Alicia. Cine continuado. Buenos Aires: Corregidor, 1997.

Brown, J. Andrew. "Missing Gender: The Posthuman Feminine in Alicia Borinsky, Carmen Boullosa, and Eugenia Prado". Cyborgs in Latin America. Nueva York: Palgrave MacMillan, 2010. 43-76.

Boullosa, Carmen. Cielos de la tierra. México: Alfaguara, 1997.

Burroughs, Edgar Rice. A Princess of Mars. Nueva York: Dover, 1964.

Butler, Judith. Gender Trouble: Feminism and the Subversion of Identity. Londres: Routledge, 2006.

Cohen, Jeffrey Jerome. "Monster Theory (Seven Theses)". Monster Theory. Jeffrey Jerome Cohen, ed. Minneapolis: U of Minnesota P, 1996. 3-20.

Cirlot, J. E. A Dictionary of Symbols. Jack Sage, trad. Nueva York: Dorset, 1971.

Cixous, Hélène. "The Laugh of the Medusa." French Feminism Reader. Kelly Oliver, ed. Lanham, MD: Rowman and Littlefield, 2000. 257-275.

Dávila, Verónica. "La literatura puertorriqueña femenina y ciencia ficción ante una crisis de la escritura: Mirada a dos cuentos de Marta Aponte Alsina”. Inédito.

Derrida, Jacques. "The Law of Genre." On Narrative. Avital Ronnell, trad. W. J. T. Mitchell, ed. Chicago: U of Chicago P, 1981. 51-78.

Farmer, Philip José. The Lovers. Nueva York: Ballantine Books, 1961.

Fideli, Finisia. "O ovo do tempo". Dinossauria tropicalia. São Paulo: GRD, 1994. 3-31.

Ginway, M. Elizabeth. "Do implantado ao ciborgue: O corpo social na ficção científica brasileira". Revista Iberoamericana LXXIII/211 (2007): 787-800. 
"Recent Brazilian Science Fiction and Fantasy Written by Women.” Foundation 99 (2007): 49-62.

"Finisia Fideli: Finding the Female Voice in Brazilian Science Fiction." Femspec X/1 (2009): 66-82.

González Rodríguez, Sergio. “Los libros del 2008”. Reforma 4 ene. 2009.

Gorodischer, Angélica. "Los embriones del violeta". Lo mejor de la ciencia ficción latinoamericana. Bernard Goorden y A. E. Van Vogt, eds. Barcelona: Martínez Roca, 1982. 122-156.

Gundermann, Eva. Desafiando lo abyecto: una lectura feminista de "Mejor desaparece" de Carmen Boullosa. Frankfurt: Peter Lang, 2002.

Gutiérrez, Diana. "Crea Tarazona una novela sobre el delirio". Reforma (México) 18 oct. 2008.

Haraway, Donna. “A Cyborg Manifesto: Science, Technology, and Socialist-Feminism in the Late Twentieth Century." Simians, Cyborgs and Women: The Reinvention of Nature. Nueva York; Routledge, 1991. 149-181.

Hayles, N. Katherine. How We Became Posthuman: Virtual Bodies in Cybernetics, Literature, and Informatics. Chicago: U of Chicago P, 1999.

Hind, Emily. Femmenism and the Mexican Woman Intellectual from Sor Juana to Poniatowska. Nueva York: Palgrave McMillan, 2010.

Hoeg, Jerry. Science, Technology, and Latin American Narrative in the Twentieth Century and Beyond. Bethlehem: Lehigh UP, 2000.

Ives, Kelly. Cixous, Irigaray, Kristeva: The Jouissance of French Feminism. Kent, UK: Crescent Moon, 1998. Impreso.

Kristeva, Julia. "Powers of Horror." The Portable Kristeva. Kelly Oliver, ed. Nueva York: Columbia UP, 2002. 299-232.

"Maternity, Feminism, and Language." French Feminism Reader. Kelly Oliver, ed. Lanham, MD: Roman and Littleman, 2000. 153-200.

Kuhnheim, Jill. "Postmodern Feminist Nomadism in Carmen Boullosa's Duerme." Letras Femeninas XXVII/2 (2001): 8-23.

Kulawik, Kryzystof. “Asediar la literatura, la política y la cultura: conversación con la escritora chilena Eugenia Prado Bassi”. Revista Nomadias XVI (2012): 227-246. $<$ http://www.revistas.uchile.cl/index.php/NO/article/viewFile/25019/26370>. 14 feb. 2014.

Moers, Ellen. Literary Women. Garden City, NY: Doubleday, 1976.

Niebylski, Dianna. "Spectacle and Nomadic Bodies in Alicia Borinsky's Mina cruel y Cine continuado." Letras femeninas XXVII/2 (2001): 54-67.

Oliver, Kelly, ed. French Feminism Reader. Lanham, MD: Rowman and Littlefield, 2000.

Prado, Eugenia. Lóbulo. Santiago: Cuarto Propio. 1998. 
Shelley, Mary. Frankenstein or the Modern Prometheus. Johanna M. Smith, ed. Boston: Bedford/St. Martin P, 2000.

Tarazona, Daniela. El animal sobre la piedra. México, DF: Almadía, 2008.

Taylor, Claire. "Cities, Codes and Cyborgs in Carmen Boullosa's Cielos de la tierra." Bulletin of Spanish Studies LXXX/4 (2003): 477-93.

Todorov, Tzvetan. The Fantastic: A Structural Approach to a Literary Genre. Cleveland: Case Western UP, 1973. 